\title{
Tyrosine phosphorylation and bacterial virulence
}

\author{
Sarah E Whitmore and Richard J Lamont \\ Protein phosphorylation on tyrosine has emerged as a key device in the control of numerous cellular functions in bacteria. In this article, \\ we review the structure and function of bacterial tyrosine kinases and phosphatases. Phosphorylation is catalyzed by \\ autophosphorylating adenosine triphosphate-dependent enzymes (bacterial tyrosine (BY) kinases) that are characterized by the \\ presence of Walker motifs. The reverse reaction is catalyzed by three classes of enzymes: the eukaryotic-like phosphatases (PTPs) and \\ dual-specific phosphatases; the low molecular weight protein-tyrosine phosphatases (LMW-PTPs); and the polymerase-histidinol \\ phosphatases (PHP). Many BY kinases and tyrosine phosphatases can utilize host cell proteins as substrates, thereby contributing to \\ bacterial pathogenicity. Bacterial tyrosine phosphorylation/dephosphorylation is also involved in biofilm formation and community \\ development. The Porphyromonas gingivalis tyrosine phosphatase Ltp1 is involved in a restraint pathway that regulates heterotypic \\ community development with Streptococcus gordonii. Ltp1 is upregulated by contact with S. gordonii and Ltp 1 activity controls \\ adhesin expression and levels of the interspecies signal Al-2.
}

International Journal of Oral Science (2012) 4, 1-6; doi:10.1038/ijos.2012.6; published online 2 March 2012

Keywords: oral biofilm; Porphyromonas gingivalis; Streptococcus; tyrosine phosphorylation; virulence

\section{INTRODUCTION}

Regulation of protein activity, as orchestrated by the tightly coordinated and balanced dynamics between kinases and phosphatases, is one of the critical determinants of normal cellular growth and development. While the addition or removal of phosphoryl groups to/from serine, threonine or tyrosine residues has long been established as one of the predominant mechanisms of post-translational protein modification in eukaryotes, it was not until the 1970s that landmark studies demonstrated its importance in prokaryotes. ${ }^{1}$ Furthermore, protein phosphorylation has now also been shown to be prevalent in archaea. ${ }^{2}$ The first characterized phosphorylation systems in prokaryotic organisms were the two component systems (TCS) and the phosphotransferase system (PTS). ${ }^{3}$ In the basic configuration of TCS, a surface-exposed sensor kinase is first autophosphorylated in response to an external signal. The phosphoryl group is then transferred to the aspartyl residue of a response regulator, which in turn can modulate gene expression. In this manner, signal transduction is effectuated by phosphate flow. TCS are widespread in bacteria, and they control the response to a wide range of environmental stimuli. Remarkably, any one organism can possess up to 50 functionally isolated systems. In the PTS system, a phosphoryl group from phosphoenol pyruvate is transferred along a chain of proteins by reversible phosphorylation of histidine residues (although HPr is phosphorylated on histidine and serine). ${ }^{3}$ The final receptor for the phosphoryl group is a sugar; hence, the PTS is involved in carbohydrate uptake rather than signal transduction.

\section{PHOSPHORYLATION OF PROTEINS IN BACTERIA}

Serine and threonine phosphorylation

Bacterial serine/threonine specific phosphorylation was discovered more than 30 years ago, and this post-translational modification is now known to be ubiquitous and is involved in a diverse array of physiological processes including secondary metabolism, catabolite repression, oxidative stress responses and sporulation. ${ }^{4}$ Serine/threonine kinases and phosphatases are also involved in bacterial virulence, in particular through their action on host cell substrates (Table 1). For example, the YpkA/YopO kinase of Yersinia species is delivered into epithelial cells by type III secretion machinery, whereupon it disrupts actin microfilament structure. ${ }^{5}$ Two autophosphorylated Ser/Thr protein kinases, NleH1 and NleH2, in enterohemorrhagic Escherichia coli, and the OspG protein in Shigella flexneri, inhibit activation of the proinflammatory transcription factor NF- $\kappa B .{ }^{6-7}$ The serine phosphatase SerB of Porphyromonas gingivalis, which is required for maximal invasion of the organisms into epithelial cells, can impact both the actin and tubulin cytoskeleton of host cells, and also attenuate NF- $\kappa \mathrm{B}$ activation. ${ }^{8-10}$ The secretion of serine kinases and/or phosphatases has thus afforded bacterial pathogens the means to interfere with host signal transduction pathways.

Tyrosine phosphorylation

The first definitive evidence of protein tyrosine kinase activity in bacteria was discovered in E. coli with the identification of phosphotyrosine in partial acid hydrolysates of proteins. ${ }^{11}$ Protein tyrosine phosphorylation subsequently was shown to direct many essential 
Table 1 Bacterial kinases and phosphatases involved in virulence through interaction with host cell proteins

\begin{tabular}{|c|c|c|c|c|}
\hline Organism & Enzyme & Activity & Impact on host cell function & References \\
\hline Coxiella burnetii & Acp & Tyrosine phosphatase & Inhibition of human neutrophils & $55-56$ \\
\hline Enterohemorrhagic & $\mathrm{NleH} 1, \mathrm{NleH} 2$ & Ser/Thr kinase & Inhibit activation of NF-kB & 6 \\
\hline Escherichia coli & $\mathrm{NleH} 1, \mathrm{NleH} 2$ & Ser/Thr kinase & Inhibit activation of NF-kB & 6 \\
\hline \multirow[t]{2}{*}{ Mycobacterium tuberculosis } & MPtpA and B & Tyrosine phosphatase & Phagocytosis actin polymerization in macrophages & 35,57 \\
\hline & $P k n G$ & Ser/Thr kinase & Inhibition of phagosome-lysosome fusion & 58 \\
\hline Porphyromonas gingivalis & SerB & Serine phosphatase & $\begin{array}{l}\text { Disruption of actin/tubulin; inhibition of NF-kB activation, } \\
\text { intracellular persistence }\end{array}$ & $9-10$ \\
\hline Salmonella 'typhimurium' & SptP & Tyrosine phosphatase & Actin rearrangements & 60 \\
\hline \multirow[t]{2}{*}{ Shigella flexneri } & OspG & Ser/Thr kinase & Inhibit NF-кB activation & 6 \\
\hline & OspF & Dual specific phosphatase & Represses innate immunity & 61 \\
\hline Yersinia enterocolitica & YopO & Ser/Thr kinase & Disruption of actin; inhibition of phagocytosis & 62 \\
\hline Yersinia pseudotuberculosis & YopH & Tyrosine phosphatase & Cytoskeletal rearrangements; inhibition of phagocytosis & 28 \\
\hline Yersinia pseudotuberculosis & YpkA & Ser/Thr kinase & Disruption of actin; inhibition of phagocytosis & 5 \\
\hline
\end{tabular}

Table 2 Bacterial protein tyrosine kinases and phosphatases and their functional roles

\begin{tabular}{|c|c|c|c|c|c|}
\hline Organism & Tyrosine Kinase & $\begin{array}{l}\text { Tyrosine } \\
\text { Phosphatase }\end{array}$ & Substrate(s) & Function & References \\
\hline Acinetobacter johnsonii & Ptk & Ptp & $\begin{array}{l}\text { Ptp uses Ptk as endogenous } \\
\text { substrate }\end{array}$ & $\begin{array}{l}\text { Phosphorelay reactions of inner } \\
\text { membrane proteins }\end{array}$ & 63 \\
\hline Acinetobacter Iwoffii & Wzc & Wzb & $\begin{array}{l}\text { Wzb uses Wzc as endogenous } \\
\text { substrate }\end{array}$ & Emulsan production & 46 \\
\hline Bacillus subtilis & $\begin{array}{l}\text { YwqD, PtkA, PtkB, } \\
\text { McsB }\end{array}$ & $\begin{array}{l}\text { YwqE, YfkJ, YwlE, } \\
\text { PtpZ }\end{array}$ & $\begin{array}{l}\text { TuaD, Ugd, SsbA, McsA, CtsR, YjoA, } \\
\text { YnfE, TvyG, YorK, Asd, YwpH }\end{array}$ & $\begin{array}{l}\text { Exopolysaccharide synthesis, } \\
\text { teichuronic acid production, DNA } \\
\text { metabolism, heat shock response }\end{array}$ & $64-65$ \\
\hline Caulobacter crescentus & DivL & - & CtrA & Cell division & 66 \\
\hline Erwinia amylovora & AmsA & Amsl & Lipid carrier di-/monophosphates & Amylovoran production & 67 \\
\hline Escherichia coli K-12 & $W_{Z C} C_{C A}$ & Wzb & $\begin{array}{l}\text { Ugd; Wzb uses Wzc as endogenous } \\
\text { substrate }\end{array}$ & Colanic acid synthesis & 40,68 \\
\hline Escherichia coli K-12/K-30 & Etk & Etp & RpoH, RseA; Etk & Exopolysaccharide production & 69 \\
\hline Escherichia coli K-30 & $W_{Z C} C_{C P S}$ & Wzb & Ugd & Group 1 capsule assembly & 44 \\
\hline Klebsiella pneumonia & Yco6, Wzc & Yor5, Wzb & $\begin{array}{l}\text { Yor5 uses Yco6 as endogenous } \\
\text { substrate }\end{array}$ & Capsule synthesis & 18,70 \\
\hline Myxococcus xanthus & MasK & - & $\mathrm{Mg} \mid \mathrm{A}$ & $\begin{array}{l}\text { Aggregation, sporulation, motility, } \\
\text { development }\end{array}$ & 71 \\
\hline Porphyromonas gingivalis & & Ltp1 & & $\begin{array}{l}\text { Exopolysaccharide production, } \\
\text { heterotypic community development }\end{array}$ & 49 \\
\hline Pseudomonas aeruginosa & WaaP & & & Lipopolysaccharide synthesis & 72 \\
\hline Pseudomonas aeruginosa & $42 k$ & & Flagellin $a$ and b proteins; & Flagellin export & 73 \\
\hline Pseudomonas aeruginosa & & TbpA & Diguanylate cyclase & $\begin{array}{l}\text { Exopolysaccharide production, biofilm } \\
\text { development }\end{array}$ & 47 \\
\hline Ralstonia solanacearum & EpsB & EpsP & & Exopolysaccharide transport & $74-75$ \\
\hline Salmonella typhimurium & PutA & - & P5C & Proline metabolism & 76 \\
\hline Sinorhizobium meliloti & ExoP & - & & Succinoglycan production & 77 \\
\hline Staphylococcus aureus & Cap5B2 & CapC, PtpA, PtpB & $\begin{array}{l}\text { Cap50 (UDP-acetyl-mannosamine } \\
\text { dehydrogenase) }\end{array}$ & Capsule synthesis & 78 \\
\hline Streptococcus agalactiae & CpsD & CpsB & & Polysaccharide chain length & 79 \\
\hline Streptococcus pneumoniae & CpsD & CpsB & & Capsule synthesis & 80 \\
\hline Streptococcus thermophilus & EpsD & EpsB & EpsE & Exopolysaccharide biosynthesis & 81 \\
\hline Streptomyces coelicolor A3(2) & $\begin{array}{l}\text { AfsK } \\
\text { Sc05717 }\end{array}$ & - & AfsR & $\begin{array}{l}\text { Antibiotic production } \\
\text { Cell growth }\end{array}$ & $82-84$ \\
\hline
\end{tabular}

cellular processes, such as capsule production, growth, proliferation, migration, flagellin export, adaptation to stress and production of secondary metabolites (Table 2). ${ }^{12}$ Moreover, the addition of a bulky, negatively charged phosphoryl group to a protein can influence both cellular location and the overall protein interactome. ${ }^{13} \mathrm{~A}$ number of global phosphoproteome studies have now been conducted in bacteria, including E. coli, Helicobacter pylori, Bacillus subtilis, Streptomyces coelicolor, Mycoplasma pneumoniae, Streptococcus pneumoniae, Klebsiella pneumoniae, Lactococcus lactis, Campylobacter jejuni and Pseudomonas species. These databases have shown an increasing number of bacterial proteins that are phosphorylated on Ser/Thr/Tyr residues; and, moreover, these proteins are involved 
in a variety of important cellular functions, including virulence and cell survival. ${ }^{14-24}$

\section{BACTERIAL TYROSINE KINASES}

\section{Structure}

The bacterial tyrosine (BY) kinase family comprises the major group of bacterial enzymes endowed with tyrosine kinase activity. In most cases, BY kinases possess a transmembrane domain that can function both as an anchor and a sensor, as well as an intracellular catalytic domain. ${ }^{25}$ The catalytic domain lacks the distinctive eukaryotic kinase motifs, and is defined by the presence of Walker A (P-loop) and B motifs (Figure 1). In addition, some BY kinases also contain a Walker $\mathrm{A}^{\prime}$ motif. BY kinases autophosphorylate at a tyrosine rich cluster in the C-terminal region using adenosine triphosphate as a phosphoryl donor, and the degree of phosphorylation in this region determines the interaction strength with other proteins. Some BY kinases also autophosphorylate on a tyrosine residue in close proximity to the Walker A' box. Recent studies have identified other bacterial tyrosine kinases including those that closely resemble eukaryotic-like kinases, and those that utilize guaidino-phosphotransferase domains. Additionally, in some cases, tyrosine can substitute for histidine in TCS. $^{25}$

\section{Function}

The majority of genes encoding BY kinases reside in operons responsible for regulating the synthesis and secretion of polysaccharides. The autophosphorylation state of the BY kinases exerts control over this process through phosphorylation, and activation, of UDP-sugar dehydrogenases and glucosyltransferases. ${ }^{13}$ As bacterial regulatory networks are extensively interconnected, the phosphotransfer reactions can modulate a myriad of physiological processes that include resistance to cationic peptides and polymixin, along with heat shock responses. A greater appreciation for the role of tyrosine kinases in prokaryotes has emerged from the application of global phosphoproteome technologies. For example, the PtkA BY kinase of Bacillus

Gram-negative
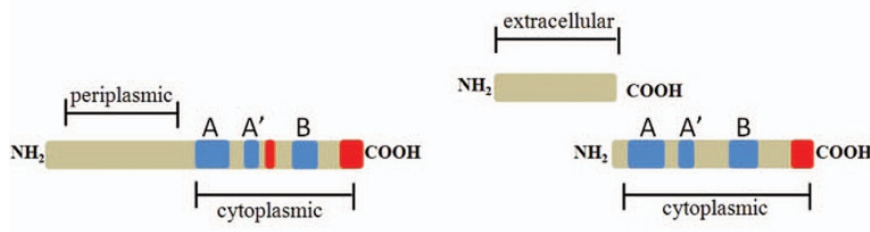

Conserved Sequence Motifs:

Walker A: GxrxxGK[ST]

Walker A' : [ILVFM](3)DxDxR

Walker B: [ILVFM](3)DxxP

Tyrosine-rich cluster

Figure 1 Domain structure of BY kinases. A periplasmic (gram-negatives) or extracellular (gram-positives) sensory loop is linked to the catalytic intracellular domain, either contiguously (gram-negatives) or through protein-protein interaction (gram-negatives). The catalytic domain contains Walker A, B and A' motifs (blue). A tyrosine-rich region (red) containing the phosphorylation sites is present in the C-terminus, and gram-negative BY kinases also possess an internal tyrosine (red) that can be autophosphorylated. Walker motifs $A, A^{\prime}$ and $B$ can be identified by conserved sequences motifs. BY, bacterial tyrosine. subtilis can phosphorylate at least nine different protein substrates. ${ }^{26}$ Several of these substrates, most notably single-stranded DNA exonuclease YorK and aspartate semialdehyde dehydrogenase Asd, are activated via phosphorylation. Yet, the activity of many others, such as enolase, YjoA, YnfE, TvyG, Ugd and SsbA, remains unaffected by phosphorylation, and rather the cellular localization of these proteins is governed by phosphorylation status. Hence, BY action can not only regulate the activity of substrates, but also ensure the correct cellular localization of specific protein targets.

\section{BACTERIAL TYROSINE PHOSPHATASES}

\section{Structure}

Bacterial tyrosine phosphatases catalyze the dephosphorylation of tyrosyl phosphorylated proteins, which in turn can result in either the propagation or inhibition of phospho-dependent signaling. Bacterial tyrosine phosphatases can be categorized into three distinct families: (i) the eukaryotic-like phosphatases (PTPs) and dual-specific phosphatases that also display activity against phosphoserine and phosphothreonine; (ii) the low molecular weight protein-tyrosine phosphatases (LMW-PTPs), a family of small acidic enzymes also found in eukaryotes; and (iii) the polymerase-histidinol phosphatases (PHP), a family of phosphoesterases commonly found in grampositive bacteria. The PTP, dual-specific phosphatase and LMWPTP enzymes utilize a common catalytic mechanism that involves the conserved signature $\mathrm{C}(\mathrm{X})_{5} \mathrm{R}$ motif in the phosphate binding loop where cysteine, functioning as a nucleophile, attacks the phosphorus atom of the phosphotyrosine residue of the substrate. The arginine residue interacts with the phosphate moiety of the phosphotyrosine. ${ }^{27}$ This motif is flanked, more remotely, by an essential aspartic acid residue, the location of which varies among the families. Protein tyrosine phosphatases also are capable of possessing dual functions, whereby in some instances, they can stimulate actions of cognate protein tyrosine kinases, yet in other cases, they may antagonize those actions. ${ }^{12}$ In gram-negative bacteria, the gene encoding the LMW-PTP generally is upstream of the tyrosine kinase in the same operon. Conversely, in gram-positives, a PHP type phosphatase often is located in the same operon as the BY kinase alongside an adaptor protein, with the gene for the LMW-PTP at a remote site.

\section{Function}

While bacterial tyrosine phosphatases can be intimately involved in a number of cellular processes, two major themes have become apparent: involvement in polysaccharide production; and as secreted effector proteins with the potential for manipulation of host cell signal transduction pathways. Polysaccharide production, encompassing both exopolysaccharides and capsular polysaccharides, is also a key virulence determinant in many organisms and thus tyrosine phosphatase activity is emerging as a central player in the information flow that controls pathogenic activity.

The YopH protein tyrosine phosphatase of Yersinia, a member of the PTP family, is an essential virulence factor that is injected into epithelial cells by type III secretion machinery. YopH can uncouple multiple signal transduction pathways, ${ }^{28}$ and in human epithelial cells YopH dephosphorylates several focal adhesion proteins, including p130Cas (Cas), focal adhesion kinase and paxillin. ${ }^{29-31}$ Similarly, Salmonella 'typhimurium' translocates the PTP tyrosine phosphatase SptP into epithelial cells where it is involved in reversing mitogen-activated protein kinase activation. ${ }^{32} \mathrm{SptP}$ is required for full virulence in murine models of disease. ${ }^{33}$ Shigella flexneri produces a dually specific phosphatase, OspF, that dephosphorylates mitogen-activated protein kinase, which consequently prevents histone $\mathrm{H} 3$ phosphorylation. ${ }^{34}$ 
A reduction in the level of histone 3 phosphorylation impedes access of the transcription factor NF- $\kappa \mathrm{B}$ to the chromosome and hence transcription of NF- $\kappa \mathrm{B}$ responsive genes such as IL-8 is reduced. Thus, OspF activity allows $S$. flexneri to modulate host cell epigenetic information as a strategy for repressing innate immunity. Mycobacterium tuberculosis secretes two LMW-PTPs, PtpA and PtpB. ${ }^{35}$ The predicted lack of tyrosine kinases in the M. tuberculosis genome suggests a dedicated role for these phosphatases in regulation of host cell functions. Expression of $p t p A$ in M. tuberculosis is upregulated within monocytes, and a $p t p B$ mutant is impaired in its ability to grow in human macrophages ${ }^{36}$ and survive in a guinea pig model. ${ }^{37}$ These phosphatases appear to function by impacting actin polymerization within macrophages and thereby affecting phagocytosis of the organism. ${ }^{38}$ A recently identified phosphatase, LipA, in L. monocytogenes has a predicted structure bearing a remarkable semblance to the PtpB phosphatase. ${ }^{39}$ Moreover, both LipA and PtpB share a unique feature whereby they possess dual-function activities as phosphotyrosine and phosphoinositide phosphatases, and both harbor the potential to play pivotal roles in bacterial virulence.

In addition to physical protection, exopolysaccharide such as capsule is often poorly immunogenic and can mask protein antigens and receptors for complement and phagocytic cells. In many cases, dephosphorylation of tyrosine kinases increases the level of polysaccharide synthesis, ${ }^{4}$ as evidenced by the activity of the E. coli K-12 BY kinase Wzc-ca, which is regulated by its cognate LMW-PTP, Wzb. ${ }^{40}$ In this system, production of the capsular exopolysaccharide colonic acid is maximal when Wzc-ca is dephosphorylated by Wzb. Similarly, in Streptococcus pneumoniae autophosphorylation of the CpsD kinase, when in the presence of its cognate partner, CpsC, results in the attenuation of CpsD kinase activity, as well as a reduction in the level of encapsulation via a negative feedback regulatory loop. ${ }^{41}$ Consequently, the PHP family phosphatase CpsB can control capsule production via dephosphorylation of $\mathrm{CpsD}$ which functions as a reversible switch. ${ }^{42}$ The converse situation also exists. In clinical isolates of S. pneumoniae, phosphorylation of CpsD increases capsule production under anaerobic conditions, ${ }^{43}$ and in E. coli K30 the assembly of group I capsular polysaccharides is elevated by phosphorylation of Wzc-cps. ${ }^{44}$ Undoubtedly, the interplay among tyrosine kinases, phosphatases and exopolysaccharide is of a nuanced and subtle nature that may be reconfigured according to environmental conditions. Indeed, metabolic activity is one factor that has been shown to influence kinase to phosphatase ratios. ${ }^{45-46}$

\section{Role in biofilms}

A recent study in Pseudomonas aeruginosa demonstrated that tyrosine phosphatase activity is a unifying element that amalgamates polysaccharide production and biofilm formation with quorum sensing. ${ }^{47}$ The PTP family tyrosine phosphatase, TpbA, is a negative regulator of 3,5-cyclic diguanylic acid (c-di-GMP), an important second messenger which suppresses transcription across the pel operon that encodes for extracellular matrix polysaccharide. Lower levels of exopolysaccharide in turn lead to reduced biofilm formation. In addition, TpbA responds to acyl homoserine lactone, and $t p b A$ is regulated positively by the LasR transcriptional regulator. TpbA also regulates cell lysis as a means to control extracellular DNA that is used for complex biofilm maturation. ${ }^{48}$ These findings also reveal a previously unrecognized ability for phospho-dependent signaling to intersect with other important cellular second messenger systems.

Tyrosine phosphatases can also control heterotypic biofilm formation among oral organisms. P. gingivalis accumulates into heterotypic

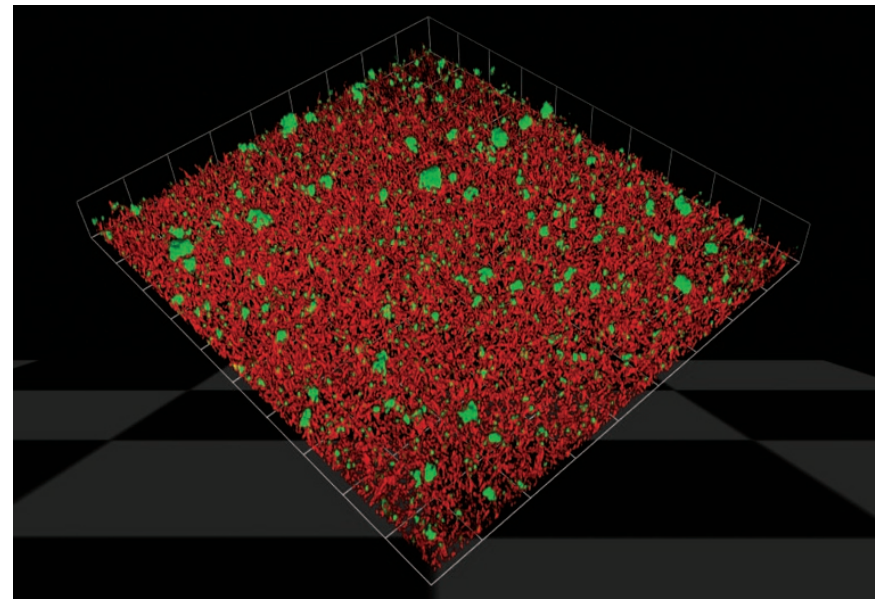

Figure 2 Porphyromonas gingivalis (green) accumulates into a mixed species community on a substratum of Streptococcus gordonii (red). Image courtesy of Dr Christopher Wright.

communities with the antecedent oral biofilm colonizer S. gordonii (Figure 2). Maeda et al. ${ }^{49}$ identified a LMW-PTP, Ltp1, in P. gingivalis which functions as a negative regulator of EPS production, as well as community formation with S. gordonii. Transcription of ltpl is increased following contact with S. gordonii, ${ }^{50}$ and Ltp1 is a component of a signaling pathway that converges on the LuxR family transcriptional regulator CdhR. ${ }^{51}$ The expression of the $P$. gingivalis $\mathrm{Mfa}$ fimbriae and of LuxS, both of which contribute to community development with $S$. gordonii, are negatively regulated by CdhR (Figure 3 ). Thus, in both $P$. aeruginosa and $P$. gingivalis, tyrosine phosphatase activity results in arrested community development which may maintain optimal biofilm architecture.

\section{CONCLUSION}

It is sobering to reflect that until fairly recently, post-translational modification of tyrosine residues by phosphorylation was believed to be an indicator of the sophisticated regulatory networks characteristic of eukaryotic systems. Since then, research on bacterial tyrosine kinases and phosphatases has proceeded apace and they are now considered key contributors to bacterial cell homeostasis, virulence and even cell survival in all domains of life. Future genomics and proteomics research will decipher and dissect the underlying mechanisms of tyrosine phosphotransfer cascades in bacteria and their functional roles. Accumulating evidence reaffirms the notion that bacterial tyrosine kinases and phosphatases display exquisite substrate specificity; nevertheless, they are still capable of utilizing multiple protein substrates, both endogenous and exogenous, thereby providing versatility in phosphorelay signaling networks. Ongoing studies reveal increasing instances where bacterial kinases/phosphatases are capable of inducing post-translational modifications of host proteins and are a crucial facet of the dynamic host-pathogen relationship. Moreover, as BY kinases differ from their eukaryotic counterparts in significant biochemical and structural aspects, they provide attractive targets for specific antibacterial drugs. The crystal structures of the CapB kinase of Staphylococcus aureus and the Etk kinase of E. coli have been determined $^{52-53}$ and they exhibit a high degree of structural similarity. The availability of structural and biochemical information will facilitate the rational design of compounds that can inhibit BY kinases, while concomitantly avoiding any eukaryotic kinases. ${ }^{54}$ 


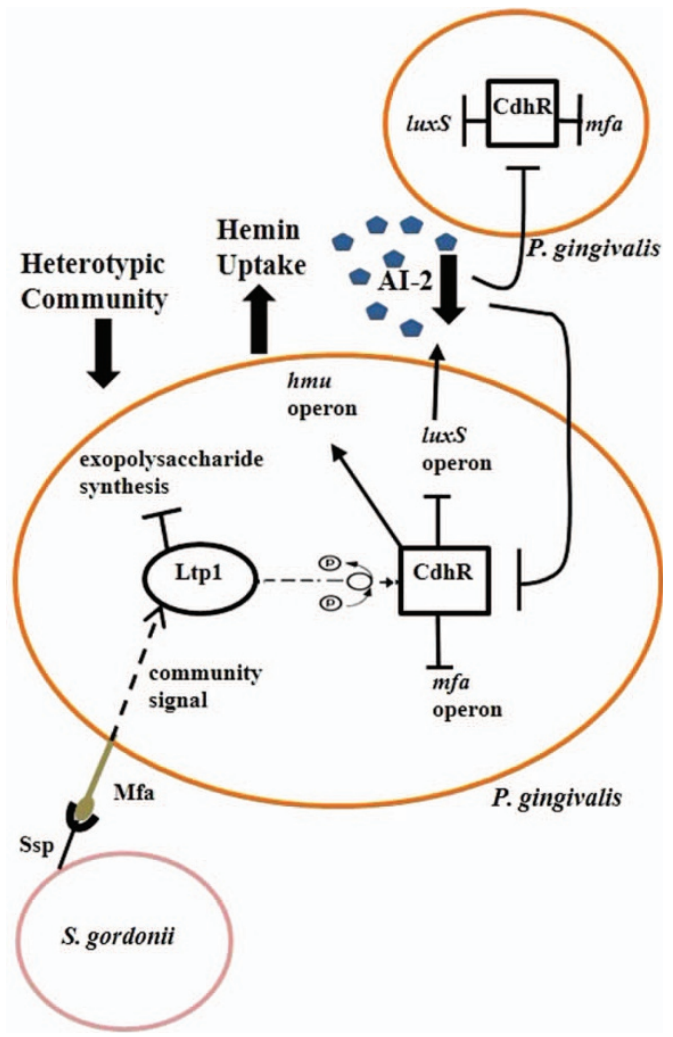

Figure 3 Model of the tyrosine phosphatase-dependent regulatory circuitry governing heterotypic community development between Porphyromonas gingivalis and Streptococcus gordonii. Initial interaction of the P. gingivalis Mfa fimbriae with $S$. gordonii activates the Ltp1 phosphatase and a signaling event is transduced via a cascade of phosphorylation/dephosphorylation events. Signaling converges on CdhR which represses transcription of the IuxS and mfa operons in $P$. gingivalis, and in turn leads to constrained $P$. gingivalis-S. gordonii community development. Lower Al-2 levels can be sensed by neighboring planktonic $P$. gingivalis cells, which also upregulate $C d h R$, thereby propagating the original streptococcal-derived signal throughout the $P$. gingivalis-S gordonii community. (Modified from Molecular Microbiology 2011; 81(2): 305-314; this material is reproduced with permission of John Wiley \& Sons, Inc.)

\section{ACKNOWLEDGEMENTS}

Research in the authors' laboratory is supported by NIH/NIDCR DE12505 and DE11111.

1 Backert S, Selbach M. Tyrosine-phosphorylated bacterial effector proteins: the enemies within. Trends Microbiol 2005; 13(10): 476-484

2 Aivaliotis M, Macek B, Gnad F et al. Ser/Thr/Tyr protein phosphorylation in the archaeon Halobacterium salinarum-a representative of the third domain of life. PLoS One 2009; 4(3): e4777.

3 Cozzone AJ, Grangeasse C, Doublet $\mathrm{P}$ et al. Protein phosphorylation on tyrosine in bacteria. Arch Microbiol 2004; 181(3): 171-181.

4 Cozzone AJ. Role of protein phosphorylation on serine/threonine and tyrosine in the virulence of bacterial pathogens. J Mol Microbiol Biotechnol2005; 9(3/4): 198-213.

5 Wiley DJ, Nordfeldth R, Rosenzweig J et al. The Ser/Thr kinase activity of the Yersinia protein kinase $A$ (YpkA) is necessary for full virulence in the mouse, mollifying phagocytes, and disrupting the eukaryotic cytoskeleton. Microb Pathog 2006; 40(5): 234-243.

6 Gao X, Wan F, Mateo K et al. Bacterial effector binding to ribosomal protein s3 subverts NF-kB function. PLoS Pathog 2009; 5(12): e1000708.

7 Royan SV, Jones RM, Koutsouris A et al. Enteropathogenic E. coli non-LEE encoded effectors NleH1 and NleH2 attenuate NF-kB activation. Mol Microbiol 2010; 78(5): 1232-1245.

8 Bainbridge B, Verma RK, Eastman C et al. Role of Porphyromonas gingivalis phosphoserine phosphatase enzyme SerB in inflammation, immune response, and induction of alveolar bone resorption in rats. Infect Immun 2010; 78(11): 45604569 .

9 Hasegawa Y, Tribble GD, Baker HV et al. Role of Porphyromonas gingivalis SerB in gingival epithelial cell cytoskeletal remodeling and cytokine production. Infect Immun 2008; 76(6): 2420-2427.

10 Tribble GD, MaoS, James CE et al. A Porphyromonas gingivalis haloacid dehalogenase family phosphatase interacts with human phosphoproteins and is important for invasion. Proc Natl Acad Sci USA 2006; 103(29): 11027-11032.

11 Manai M, Cozzone AJ. Endogenous protein phosphorylation in Escherichia coli extracts. Biochem Biophys Res Commun 1982; 107(3): 981-988.

12 Zhang ZY. Functional studies of protein tyrosine phosphatases with chemical approaches. Biochim Biophys Acta 2005; 1754(1/2): 100-107.

13 Stulke J. More than just activity control: phosphorylation may control all aspects of a protein's properties. Mol Microbiol 2010; 77(2): 273-275.

14 Ge R, Sun X, Xiao C et al. Phosphoproteome analysis of the pathogenic bacterium Helicobacter pylori reveals over-representation of tyrosine phosphorylation and multiply phosphorylated proteins. Proteomics 2011; 11(8): 1449-1461.

15 Parker JL, Jones AM, Serazetdinova L et al. Analysis of the phosphoproteome of the multicellular bacterium Streptomyces coelicolor A3(2) by protein/peptide fractionation, phosphopeptide enrichment and high-accuracy mass spectrometry. Proteomics 2010; 10(13): 2486-2497.

16 Schmidl SR, Gronau K, Pietack N et al. The phosphoproteome of the minimal bacterium Mycoplasma pneumoniae: analysis of the complete known Ser/Thr kinome suggests the existence of novel kinases. Mol Cell Proteomics 2010; 9(6): 1228-1242.

17 Sun X, Ge F, Xiao CL et al. Phosphoproteomic analysis reveals the multiple roles of phosphorylation in pathogenic bacterium Streptococcus pneumoniae. J Proteome Res 2010; 9(1): 275-282.

18 Lin MH, Hsu TL, Lin SY et al. Phosphoproteomics of Klebsiella pneumoniae NTUH$\mathrm{K} 2044$ reveals a tight link between tyrosine phosphorylation and virulence. $\mathrm{Mol} \mathrm{Cell}$ Proteomics 2009; 8(12): 2613-2623.

19 Ravichandran A, Sugiyama N, Tomita M et al. Ser/Thr/Tyr phosphoproteome analysis of pathogenic and non-pathogenic Pseudomonas species. Proteomics 2009; 9(10): 2764-2775.

20 Voisin S, Watson DC, Tessier L et al. The cytoplasmic phosphoproteome of the gramnegative bacterium Campylobacter jejuni: evidence for modification by unidentified protein kinases. Proteomics 2007; 7(23): 4338-4348.

21 Soufi B, Gnad F, Jensen PR et al. The Ser/Thr/Tyr phosphoproteome of Lactococcus lactis IL1403 reveals multiply phosphorylated proteins. Proteomics 2008; 8(17) 3486-3493.

22 Macek B, Mijakovic I, Olsen JV et al. The serine/threonine/tyrosine phosphoproteom of the model bacterium Bacillus subtilis. Mol Cell Proteomics 2007; 6(4):697-707.

23 Macek B, Gnad F. Soufi B et al. Phosphoproteome analysis of E. coli reveals evolutionary conservation of bacterial Ser/Thr/Tyr phosphorylation. Mol Cell Proteomics 2008; 7(2): 299-307.

24 Soufi B, Jers C, Hansen ME et al. Insights from site-specific phosphoproteomics in bacteria. Biochim Biophys Acta 2008; 1784(1): 186-192

25 Grangeasse C, Cozzone AJ, Deutscher J et al. Tyrosine phosphorylation: an emerging regulatory device of bacterial physiology. Trends Biochem Sci 2007; 32(2): 86-94.

26 Jers C, Pedersen MM, Paspaliari DK et al. Bacillus subtilis BY-kinase PtkA controls enzyme activity and localization of its protein substrates. Mol Microbiol 2010; 77(2): 287-299.

27 Tiganis T. Protein tyrosine phosphatases: dephosphorylating the epidermal growth factor receptor. IUBMB Life 2002; 53(1): 3-14.

28 Bliska JB. Yop effectors of Yersinia spp. and actin rearrangements. Trends Microbio 2000, 8(5): 205-208

29 Black DS, Montagna LG, Zitsmann S et al. Identification of an amino-terminal substrate-binding domain in the Yersinia tyrosine phosphatase that is required for efficient recognition of focal adhesion targets. Mol Microbiol 1998; 29(5): 1263 1274

30 Persson C, Nordfelth R, Andersson K et al. Localization of the Yersinia PTPase to focal complexes is an important virulence mechanism. Mol Microbiol 1999; 33(4): 828 838.

31 Persson C, Carballeira N, Wolf-Watz H et al. The PTPase YopH inhibits uptake of Yersinia, tyrosine phosphorylation of p130Cas and FAK, and the associated accumulation of these proteins in peripheral focal adhesions. EMBO J 1997; 16(9): 2307-2318.

32 Lin SL, Le TX, Cowen DS. SptP, a Salmonella typhimurium type III-secreted protein, inhibits the mitogen-activated protein kinase pathway by inhibiting Raf activation. Cell Microbiol 2003; 5(4): 267-275.

33 Kaniga $\mathrm{K}$, Uralil J, Bliska JB et al. A secreted protein tyrosine phosphatase with modular effector domains in the bacterial pathogen Salmonella typhimurium. Mol Microbiol 1996; 21(3): 633-641.

34 Arbibe L, Kim DW, Batsche E et al. An injected bacterial effector targets chromatin access for transcription factor NF- $\mathrm{KB}$ to alter transcription of host genes involved in immune responses. Nat Immunol 2007; 8(1): 47-56.

35 Koul A, Choidas A, Treder $\mathrm{M}$ et al. Cloning and characterization of secretory tyrosine phosphatases of Mycobacterium tuberculosis. J Bacteriol 2000; 182(19): 5425 5432

36 Bach H, Papavinasasundaram KG, Wong D et al. Mycobacterium tuberculosis virulence is mediated by PtpA dephosphorylation of human vacuolar protein sorting 33B. Cell Host Microbe 2008; 3(5): 316-322. 
37 Singh B, Singh G, Trajkovic $V$ et al. Intracellular expression of Mycobacterium tuberculosis-specific 10-kDa antigen down-regulates macrophage B7.1 expression and nitric oxide release. Clin Exp Immunol 2003; 134(1): 70-77.

38 Castandet J, Prost JF, Peyron P et al. Tyrosine phosphatase MptpA of Mycobacterium tuberculosis inhibits phagocytosis and increases actin polymerization in macrophages. Res Microbiol 2005; 156(10): 1005-1013.

39 Kastner R, Dussurget O, Archambaud C et al. LipA, a tyrosine and lipid phosphatase involved in the virulence of Listeria monocytogenes. Infect Immun 2011; 79(6): 2489-2498.

40 Vincent $C$, Doublet $P$, Grangeasse $C$ et al. Cells of Escherichia coli contain a proteintyrosine kinase, Wzc, and a phosphotyrosine-protein phosphatase, Wzb. J Bacteriol 1999; 181(11): 3472-3477.

41 Morona JK, Paton JC, Miller DC et al. Tyrosine phosphorylation of CpsD negatively regulates capsular polysaccharide biosynthesis in Streptococcus pneumoniae. Mol Microbiol 2000; 35(6): 1431-1442.

42 Bender $\mathrm{MH}$, Yother J. CpsB is a modulator of capsule-associated tyrosine kinase activity in Streptococcus pneumoniae. J Biol Chem 2001; 276(51): 47966-47974.

43 Weiser JN, Bae D, Epino $\mathrm{H}$ et al. Changes in availability of oxygen accentuate differences in capsular polysaccharide expression by phenotypic variants and clinical isolates of Streptococcus pneumoniae. Infect Immun 2001; 69(9): 5430 5439.

44 Wugeditsch T, Paiment A, Hocking J et al. Phosphorylation of Wzc, a tyrosine autokinase, is essential for assembly of group 1 capsular polysaccharides in Escherichia coli. J Biol Chem 2001; 276(4): 2361-2371.

45 Niemeyer D, Becker A. The molecular weight distribution of succinoglycan produced by Sinorhizobium meliloti is influenced by specific tyrosine phosphorylation and ATPase activity of the cytoplasmic domain of the ExoP protein. J Bacteriol 2001; 183(17): 5163-5170.

46 Nakar D, Gutnick DL Involvement of a protein tyrosine kinase in production of the polymeric bioemulsifier emulsan from the oil-degrading strain Acinetobacter Iwoffii RAG-1. J Bacterio/ 2003; 185(3): 1001-1009.

47 Ueda A, Wood TK. Connecting quorum sensing, c-di-GMP, pel polysaccharide, and biofilm formation in Pseudomonas aeruginosa through tyrosine phosphatase $\mathrm{TpbA}$ (PA3885). PLoS Pathog 2009; 5(6): e1000483.

48 Ueda A, Wood TK. Tyrosine phosphatase TpbA of Pseudomonas aeruginosa controls extracellular DNA via cyclic diguanylic acid concentrations. Environ Microbiol 2010; 2(3): 449-455.

49 Maeda K, Tribble GD, Tucker CM et al. A Porphyromonas gingivalis tyrosine phosphatase is a multifunctional regulator of virulence attributes. Mol Microbiol 2008; 69(5): 1153-1164.

50 Simionato MR, Tucker CM, Kuboniwa $\mathrm{M}$ et al. Porphyromonas gingivalis genes involved in community development with Streptococcus gordonii. Infect Immun 2006; 74(11): 6419-6428.

51 Chawla A, Hirano T, Bainbridge BW et al. Community signalling between Streptococcus gordonii and Porphyromonas gingivalis is controlled by the transcriptional regulator CdhR. Mol Microbiol 2010; 78(6): 1510-1522.

52 Olivares-IIlana V, Meyer P, Bechet E et al. Structural basis for the regulation mechanism of the tyrosine kinase CapB from Staphylococcus aureus. PLoS Biol 2008; 6(6): e143

53 Lee DC, Zheng J, She YM et al. Structure of Escherichia colityrosine kinase Etk reveals a novel activation mechanism. EMBO J 2008; 27(12): 1758-1766.

54 Cozzone AJ. Bacterial tyrosine kinases: novel targets for antibacterial therapy? Trends Microbiol 2009; 17(2): 536-543.

55 Hill J, Samuel JE. Coxiella burnetii acid phosphatase inhibits the release of reactive oxygen intermediates in polymorphonuclear leukocytes. Infect Immun 2011; 79(1): 414-420.

56 Li YP, Curley G, Lopez M et al. Protein-tyrosine phosphatase activity of Coxiella burnetii that inhibits human neutrophils. Acta Virol 1996; 40(5/6): 263-272.

57 Cowley SC, Babakaiff R, Av-Gay Y. Expression and localization of the Mycobacterium tuberculosis protein tyrosine phosphatase PtpA. Res Microbiol 2002; 153(4): 233241.

58 Walburger A, Koul A, Ferrari G et al. Protein kinase G from pathogenic Mycobacteria promotes survival within macrophages. Science 2004; 304(5678): 1800-1804.

59 Arricau N, Hermant D, Waxin $\mathrm{H}$ et al. Molecular characterization of the Salmonella typhi StpA protein that is related to both Yersinia YopE cytotoxin and YopH tyrosine phosphatase. Res Microbiol 1997; 148(1): 21-26.

60 Murli S, Watson RO, Galan JE. Role of tyrosine kinases and the tyrosine phosphatase SptP in the interaction of Salmonella with host cells. Cell Microbiol 2001; 3(12): 795-810.

61 Reiterer V, Grossniklaus L, Tschon T et al. Shigella flexneri type III secreted effector OspF reveals new crosstalks of proinflammatory signaling pathways during bacterial infection. Cell Signal 2011; 23(7): 1188-1196.

62 Groves E, Rittinger K, Amstutz M et al. Sequestering of Rac by the Yersinia effector YopO blocks F cy receptor-mediated phagocytosis. J Biol Chem 2010; 285(6): 40874098.
63 Grangeasse C, Doublet P, Vincent C et al. Functional characterization of the lowmolecular-mass phosphotyrosine-protein phosphatase of Acinetobacter johnsonii. J Mol Biol 1998; 278(2): 339-347.

64 Mijakovic I, Petranovic D, Bottini N et al. Protein-tyrosine phosphorylation in Bacillus subtilis. J Mol Microbiol Biotechnol 2005; 9(3/4): 189-197.

65 Mijakovic I, Petranovic D, Macek B et al. Bacterial single-stranded DNA-binding proteins are phosphorylated on tyrosine. Nucleic Acids Res 2006; 34(5): 15881596 .

66 Wu J, Ohta N, Zhao JL et al. A novel bacterial tyrosine kinase essential for cell division and differentiation. Proc Natl Acad Sci USA 1999; 96(23): 13068-13073.

67 Bugert P, Geider K. Characterization of the ams/ gene product as a low molecular weight acid phosphatase controlling exopolysaccharide synthesis of Erwinia amylovora. FEBS Lett 1997; 400(2): 252-256.

68 Reid AN, Whitfield C. Functional analysis of conserved gene products involved in assembly of Escherichia coli capsules and exopolysaccharides: evidence for molecular recognition between Wza and Wzc for colanic acid biosynthesis. J Bacteriol 2005; 187(15): 5470-5481.

69 Ilan O, Bloch Y, Frankel G et al. Protein tyrosine kinases in bacterial pathogens are associated with virulence and production of exopolysaccharide. EMBO J 1999; 18(12): 3241-3248.

70 Preneta R, Jarraud S, Vincent $C$ et al. Isolation and characterization of a proteintyrosine kinase and a phosphotyrosine-protein phosphatase from Klebsiella pneumoniae. Comp Biochem Physiol B Biochem Mol Biol 2002; 131(1): 103-112.

71 Thomasson B, Link J, Stassinopoulos AG et al. MglA, a small GTPase, interacts with a tyrosine kinase to control type IV pili-mediated motility and development of Myxococcus xanthus. Mol Microbiol 2002; 46(5): 1399-1413.

72 Zhao X, Lam JS. WaaP of Pseudomonas aeruginosa is a novel eukaryotic type proteintyrosine kinase as well as a sugar kinase essential for the biosynthesis of core lipopolysaccharide. J Biol Chem 2002; 277(7): 4722-4730.

73 South SL, Nichols R, Montie TC. Tyrosine kinase activity in Pseudomonas aeruginosa. Mol Microbiol 1994; 12(6): 903-910.

74 Huang J, Carney BF, Denny TP et al. A complex network regulates expression of eps and other virulence genes of Pseudomonas solanacearum. J Bacteriol 1995; 177(5): 1259-1267.

75 Huang J, Schell M. Molecular characterization of the eps gene cluster of Pseudomonas solanacearum and its transcriptional regulation at a single promoter. Mol Microbiol 1995; 16(5): 977-989.

76 Ostrovsky PC, Maloy S. Protein phosphorylation on serine, threonine, and tyrosine residues modulates membrane-protein interactions and transcriptional regulation in Salmonella typhimurium. Genes Dev 1995; 9(16): 2034-2041.

77 Jofre E, Becker A. Production of succinoglycan polymer in Sinorhizobium meliloti is affected by SMb21506 and requires the $\mathrm{N}$-terminal domain of ExoP. Mol Plant Microbe Interact 2009; 22(12): 1656-1668.

78 Gruszczyk J, Fleurie A, Olivares-IIlana V et al. Structure analysis of the Staphylococcus aureus UDP-N-acetyl-mannosamine dehydrogenase Cap50 Involved in capsular polysaccharide biosynthesis. J Biol Chem 2011; 286(19): 17112-17121.

79 Rubens CE, Heggen LM, Haft RF et al. Identification of $c p s D$, a gene essential for type III capsule expression in group B streptococci. Mol Microbiol 1993; 8(5): 843855.

80 Morona JK, Morona R, Miller DC et al. Mutational analysis of the carboxy-terminal (YGX)4 repeat domain of $\mathrm{CpsD}$, an autophosphorylating tyrosine kinase required for capsule biosynthesis in Streptococcus pneumoniae. J Bacteriol 2003; 185(10): 3009-3019

81 Minic Z, Marie C, Delorme C et al. Control of EpsE, the phosphoglycosyltransferase initiating exopolysaccharide synthesis in Streptococcus thermophilus, by EpsD tyrosine kinase. J Bacteriol 2007; 189(4): 1351-1357.

82 Matsumoto A, Hong SK, Ishizuka $\mathrm{H}$ et al. Phosphorylation of the AfsR protein involved in secondary metabolism in Streptomyces species by a eukaryotic-type protein kinase. Gene 1994; 146(1): 47-56.

83 Lee Y, Kim K, Suh JW et al. Binding study of AfsK, a Ser/Thr kinase from Streptomyces coelicolor A3(2) and S-adenosyl-L-methionine. FEMS Microbiol Lett 2007; 266(2): 236-240.

84 Kumagai T, Kihara H, Watanabe W et al. A novel tyrosine-phosphorylated protein inhibiting the growth of Streptomyces cells. Biochem Biophys Res Commun 2009; 385(4): 534-538.

This work is licensed under a Creative Commons Attribution-NonCommercial-NoDerivative Works 3.0 Unported License. To view a copy of this license, visit http:// creativecommons.org/licenses/by-nc-nd/3.0 